\title{
HISTÓRIA DO DESIGN?
}

\author{
Alberto Puppi \\ Universidade Federal do Paraná \\ alberto.puppi@ufpr.br
}

\begin{abstract}
Resumo: A ideia deste artigo surgiu da constatação de que 14 entre as 15 instituições de ensino que estavam oficialmente representadas no evento "Seminário Paulista do Ensino da História do Design 2014", instituições que ministram a disciplina em cursos de design no estado de São Paulo (predominantemente), em Pernambuco e no Paraná, fazem um recorte de linha do tempo única, desde um ponto passado, comum para todos nós, designers, até um presente igualmente pontual e comum a todos. Já no Paraná, no Curso de Design de Produto da UFPR, nós temos trabalhado com outra visada, a de que não se deve tratar a sequência dos fatos e eventos da História do Design de Produto de forma unilinear: nós trabalhamos com a hipótese de que existem pelo menos quatro Histórias do Design e não apenas uma, de que existem pelo menos quatro diferentes narrativas possíveis para a construção da história do design de produto, as quais não se excluem nem se complementam, convivem umas com as outras, lado a lado, resultando desse cenário, acreditamos, um quadro mais amplo e ao mesmo tempo mais claro e organizado da complexidade da História do Design de Produto.
\end{abstract}

Palavras-chave: história do design, histórias do design, linhas simultâneas de tempo.

Abstract: The idea of this article came from the finding that 14 out of the 15 educational institutions officially represented at the event "Paulista Seminar on Teaching the History of Design 2014" make a cutting of single timeline history. Those institutions offer the discipline in courses of design in the state of São Paulo (predominantly), Pernambuco and Parana. In Paraná state, in the UFPR Product Design Class, we have been working with another target, which is that we should not treat the sequence of facts and events in the History of Product Design as a single timeline. We have been working with the hypothesis that there are at least four histories of Design and not just one. That there are at least four different possible narratives for the construction of the history of product design, which does not exclude or complement each other, they live with each other, side by side, resulting from this scenario, we believe, a broader and yet more clear and organized picture of the complexity of Product Design History 
Keywords: design history, design histories, simultaneous timelines.

\section{INTRODUÇÃO}

A pretensão deste artigo é a de apresentar o conteúdo programático e o "modus operandi" da disciplina de História do Design de Produto da UFPR.

Mas aqui interessará menos narrar a história de uma disciplina de história do design do que problematizá-la no contexto de um seminário recente que reuniu uma amostragem significativa de professores que representavam importantes instituições de ensino paulistas. Além de mais dois professores que representavam duas instituições de outros estados.

O problema surgiu quando constatei que a nossa disciplina lá na UFPR apresentou um modo muito diferenciado de abordagem, tanto do conteúdo programático quanto do seu "modus operandi", quando comparados com os das outras instituições.

E com o agravante de que, apesar da amostragem de professores de História do Design participantes do evento ser relativamente pequena em relação ao tamanho da população de professores de História do Design da nação, ela era significativa.

Daí vêm as dúvidas que insistem em não se calar:

1) Somos a única instituição nacional de ensino de design que trabalha com a modalidade de mais de uma linha de tempo para narrar a história do design?;

2) Estamos razoavelmente certos ou absolutamente equivocados ao advogar a modalidade de linhas de tempo para a história do design?

O que me interessa fazer, trazendo este tema para discussão neste $110 \mathrm{P} \& D$, é basicamente obter subsídios para me aproximar da resposta para essas duas perguntas acima.

Para tanto, apresento a seguir e na falta de publicação dos Anais do encontro (aconteceu faz pouquíssimo tempo), um resumo de uma das testemunhas oculares do Seminário, a minha mesmo, e, logo em seguida, a descrição dos conteúdos programáticos e do "modus operandi" da disciplina lecionada por mim, para que possamos concluir e debater as questões aqui levantadas.

\section{O SEMINÁRIO PAULISTA DE ENSINO DE HISTÓRIA DO DESIGN}

O Seminário Paulista de Ensino de História do Design ocorreu nos dias 2 e 3 de maio de 2014 no Salão Nobre do Centro Universitário Maria Antônia da USP, em São Paulo, coordenado cientificamente por Auresnede [Eddy] Pires Stephan (ESPM/FAAP/IED) e Marcos da Costa Braga (FAUUSP).

O evento foi organizado pelo Núcleo de Design do Centro Universitário BELAS ARTES de São Paulo, pelos Cursos de Design da ESPM-SP (Escola Superior de Propaganda e Marketing de São Paulo), da FAAP-SP (Fundação Armando Álvares Pesteado de São Paulo), da Faculdade de Arquitetura e Urbanismo da Universidade Presbiteriana MACKENZIE e da Faculdade de Arquitetura e Urbanismo da USP (Universidade de São Paulo).

No Seminário, que teve como objetivo "abrir espaço para o mapeamento da disciplina nos cursos de graduação em Design do Estado de São Paulo" [BRAGA e 
STEPHAN, 2014], foram apresentados os programas da ou das disciplinas de História do Design em 12 instituições de ensino superior e 1 de ensino técnico do estado de São Paulo (FACAMP, ESPM-SP, SÃO JUDAS TADEU, UNESP, FAU-USP, FAU-MACKENZIE, ANHEMBI-MORUMBI, FACULDADES INTEGRADAS INTERAMERICANAS, FAAP, BELAS ARTES, SENAC, UNIFIEO e ETEC-TIQUATIRA) e em 2 instituições de ensino superior de outros estados, que foram convidadas pelo comitê organizador para participar e apresentar trabalhos no evento (a UFPE e a UFPR).

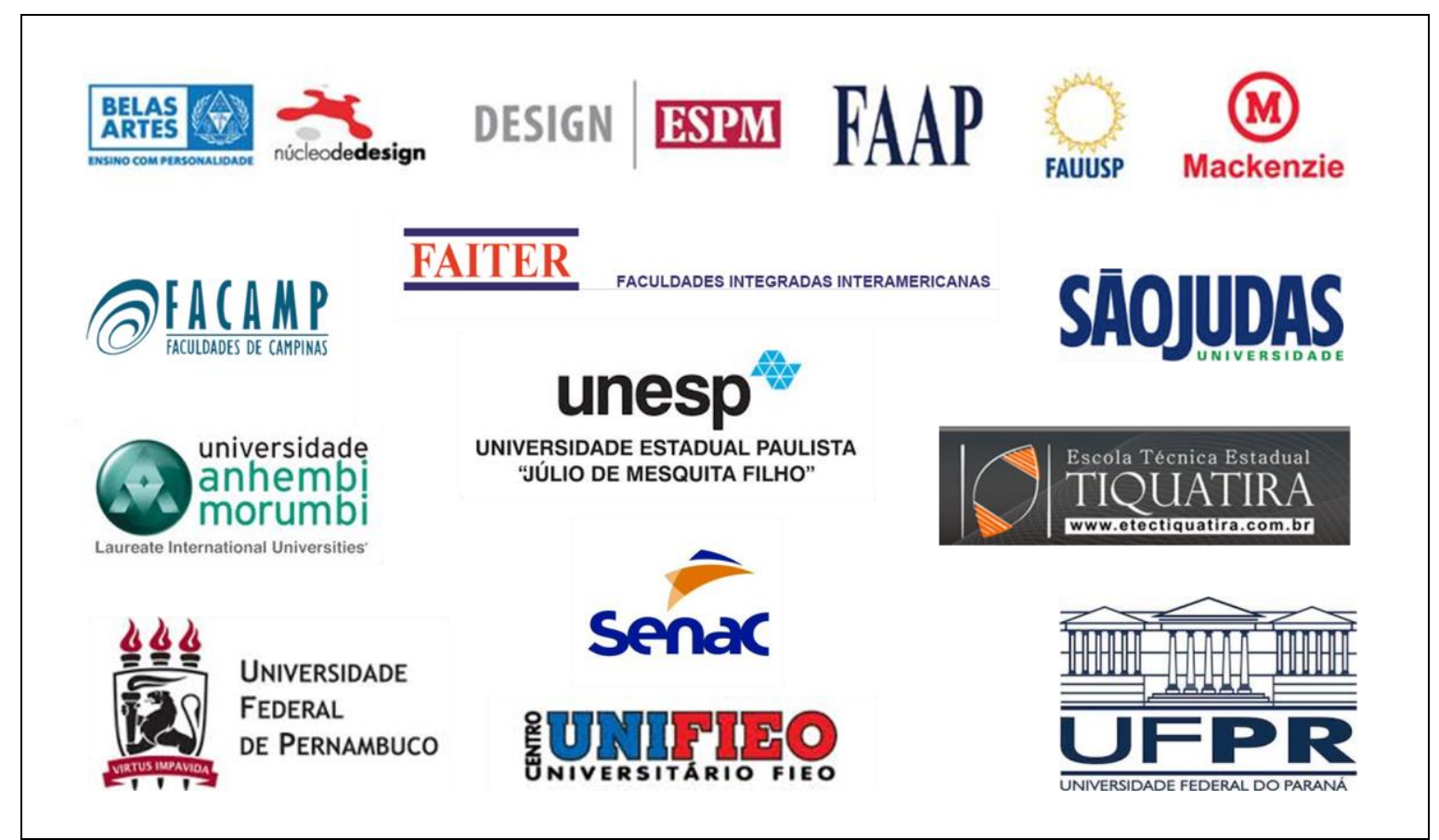

Figura 1 - Logomarcas das 15 instituições participantes.

Fonte: Folder da programação do evento, com projeto gráfico de Yeda Gonçalves de Oliveira, e homepages das próprias instituições.

Os representantes dessas 15 instituições de ensino de Design apresentaram, ao longo de dois dias de trabalho, 21 comunicações, 4 palestras e 2 mesas redondas focadas no ensino de história do design nos cursos de graduação dos estados de São Paulo, Pernambuco e Paraná.

Os anais do encontro ainda não foram publicados, mas posso dizer, como "testemunha ocular da história", pois acompanhei todas as exposições e debates do seminário, que o encontro consistiu basicamente da apresentação dos planos de ensino da(s) disciplina(s) de História do Design em cada uma das instituições participantes.

Não pude deixar de notar o que os anais comprovarão, que todas as instituições participantes, com exceção de uma, apresentaram uma organização linear da disciplina, aquela enxerga a História do Design desde uma mesma e única linha de fatos e eventos que vão se sucedendo ao longo do tempo.

Saí do encontro plenamente convencido de que a disciplina de História do Design de Produto do Curso de Design da UFPR foi a única a apresentar uma visão alternativa à da linha de tempo única.

E foi esta constatação o motivo da minha submissão deste trabalho ao P\&D, apresentar o modo peculiar de encarar a História do Design de Produto da UFPR (que 
faço na seção seguinte) e discuti-lo em âmbito mais largo que o do Seminário Paulista do Ensino da História do Design.

\section{A HISTÓRIA DO DESIGN DE PRODUTO NO CURSO DE DESIGN DA UFPR}

A disciplina de História do Design de Produto da UFPR é uma disciplina anual ofertada para alunos de primeiro ano.

O foco da disciplina é centrado na história do design internacional, com eventuais abordagens da história do design brasileiro, e minha abordagem temática procura privilegiar a história dos produtos projetados pelos designers.

Na nossa disciplina não trabalho numa perspectiva linear de evolução do design tal como sugerida por Nikolaus Pevsner [1980] em seu livro "Os Pioneiros do Design Moderno", no qual ele sugere haver uma linha única de continuidade evolutiva histórica que, no recorte temporal estabelecido por ele, evoluiria "de William Morris a Walter Gropius". Ao contrário dele, trabalho com quatro linhas de tempo distintas que separam, num primeiro momento, William Morris e Walter Gropius, e outros tantos "pioneiros" do design moderno e contemporâneo. Essas quatro linhas de tempo adotadas por nós no Curso de Design de Produto da UFPR desenrolam-se, cada uma delas, com um passado e um presente distintos, conforme a Figura $2^{1}$ abaixo, que dá uma ideia geral de como essas linhas de tempo comportam-se em conjunto:

1) História do Design Decorativo;

2) História do Design Funcionalista;

3) História do Styling;

4) História do Design Pós- Modernista.

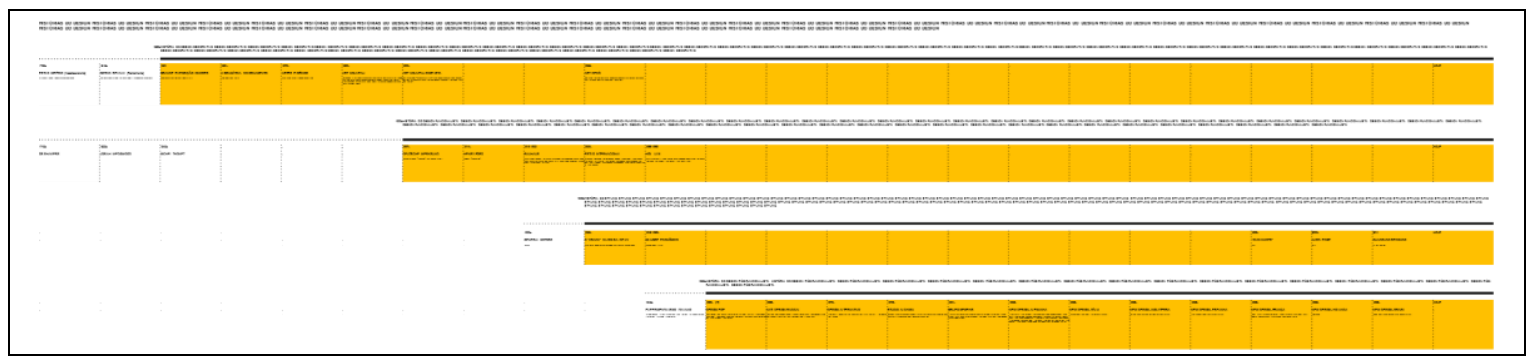

Figura 2 - As quatro linhas de tempo da História do Design na UFPR.

Fonte: "Elaborada pelo autor, com base na pesquisa realizada".

Antes de prosseguir, é bom que se diga que eu, apesar de dar aulas de história do design, nunca realizei estudos formais em História. Fui me tornando professor da disciplina de História do Design de Produto na UFPR mais por proximidade ao tema e por uma necessidade do grupo de professores do curso do que por vocação espontânea.

A minha proximidade com o tema veio do meu interesse vocacionado e da minha dedicação vitalícia à pesquisa da teoria semiótica de Charles Sanders Peirce e à pesquisa das suas possíveis aplicações ao conhecimento do design de produto.

Cedo percebi que uma das consequenciais muito interessantes desta teoria seria aplicá-la ao estudo da história do design desde o ponto de vista da linguagem. E isto é o que tenho feito sistematicamente desde então: estudar os fatos e eventos da

\footnotetext{
${ }^{1}$ Minha intenção na Figura 2 é mostrar apenas a visão geral do conjunto. Cada uma dessas linhas de tempo será detalhada ao longo do texto.
} 
história do design como fatos e eventos de criação e desenvolvimento de signos e de linguagens.

Provavelmente fui movido por uma espécie de "vício do ofício" semiótico para acabar trabalhando com estas quatro linhas de tempo distintas e independentes entre si. Mas a descoberta de que Walter Gropius não era uma espécie de sobrinho-neto de William Morris, como sugeria Pevsner [1980] e como aprendemos na escola, certamente também contribuiu para esta espécie de desconstrução da unidade histórica.

Mas o fato é que essas quatro linhas independentes de tempo foram se impondo naturalmente e, hoje, já não consigo ver de modo diferente. Parece-me que alguma lógica em proceder assim.

\subsection{História do Design Decorativo}

O recorte temporal da História do Design Decorativo começa a partir dos teóricos e designers principalmente ingleses do séc. XIX, os quais começaram a perceber a necessidade de promover uma reforma nas artes aplicadas que vinham sendo deformadas pela indústria da época. Este recorte acompanha o esforço de Owen Jones e o exemplo de William Morris, passa pela internacionalização ocidental do movimento Art Nouveau, culmina com o Art Decó, perde força, mas não termina e persiste até hoje.

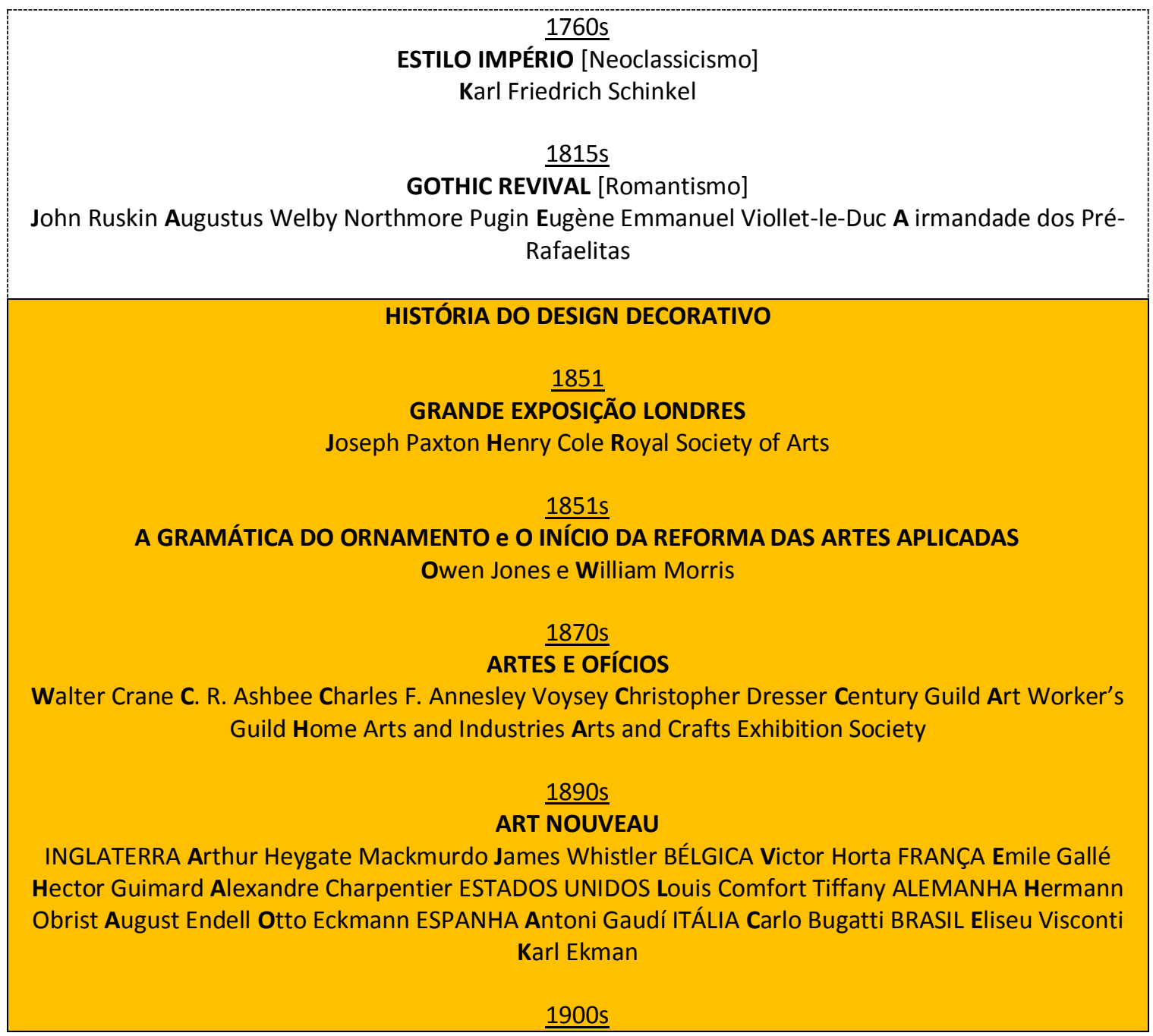




\section{ART NOUVEAU SIMPLISTA}

Henry van de Velde [ornamento "estrutural e dinamográfico"] Charles Rennie Mackintosh Wiener Sezession Adolf Loos ["Ornamento e Crime"] Deutsche Werkbund ["sachlichkeit"] Louis Sullivan ["form follws function"]

\section{$\underline{1925 \mathrm{~s}}$ \\ ART DECÓ}

Edgar Brandt Louis Süe André Mare Jacques-Emile Ruhlmann Pierre Chareau Jean Prouvé Eckart Muthesius Eileen Gray Alfonso Bialleti Renato Bialetti

HOJE

Figura 3 - Linha do tempo da História do Design Decorativo.

Fonte: "Elaborado pelo autor, com base na pesquisa realizada"

Na história do Design Decorativo, contextualizo esses projetos no âmbito do resgate cultural e da manutenção da qualidade ornamental dos produtos [READ, 1961], e não me furto a considerar aqueles objetos que foram projetados mas não foram produzidos industrialmente, como era característico na época dos movimentos Arts and Crafts [PEVSNER, 1980].

\subsection{História do Design Funcionalista}

Para a História do Design Funcionalista adoto como marco temporal inicial tanto o Deutsch Werkbund de Hermann Muthesius e Peter Behrens, na Alemanha, quanto o fordismo, nos Estados Unidos. Mas procuro deixar claro que esta linha do tempo tem uma pré-história nos produtos Shaker, na cerâmica de Wedgwood e nas cadeiras de Michael Thonet. Daí encaminho o curso para a história da Bauhaus, para a história do Estilo Internacional e para a história da escola de Ulm. Aqui também procuro mostrar que o design funcionalista continua vivo até os dias de hoje e sugiro que ele vem assumindo novas facetas, a exemplo do Design Sustentável ou do Design de Serviços, que são estudados em outra disciplina do curso.

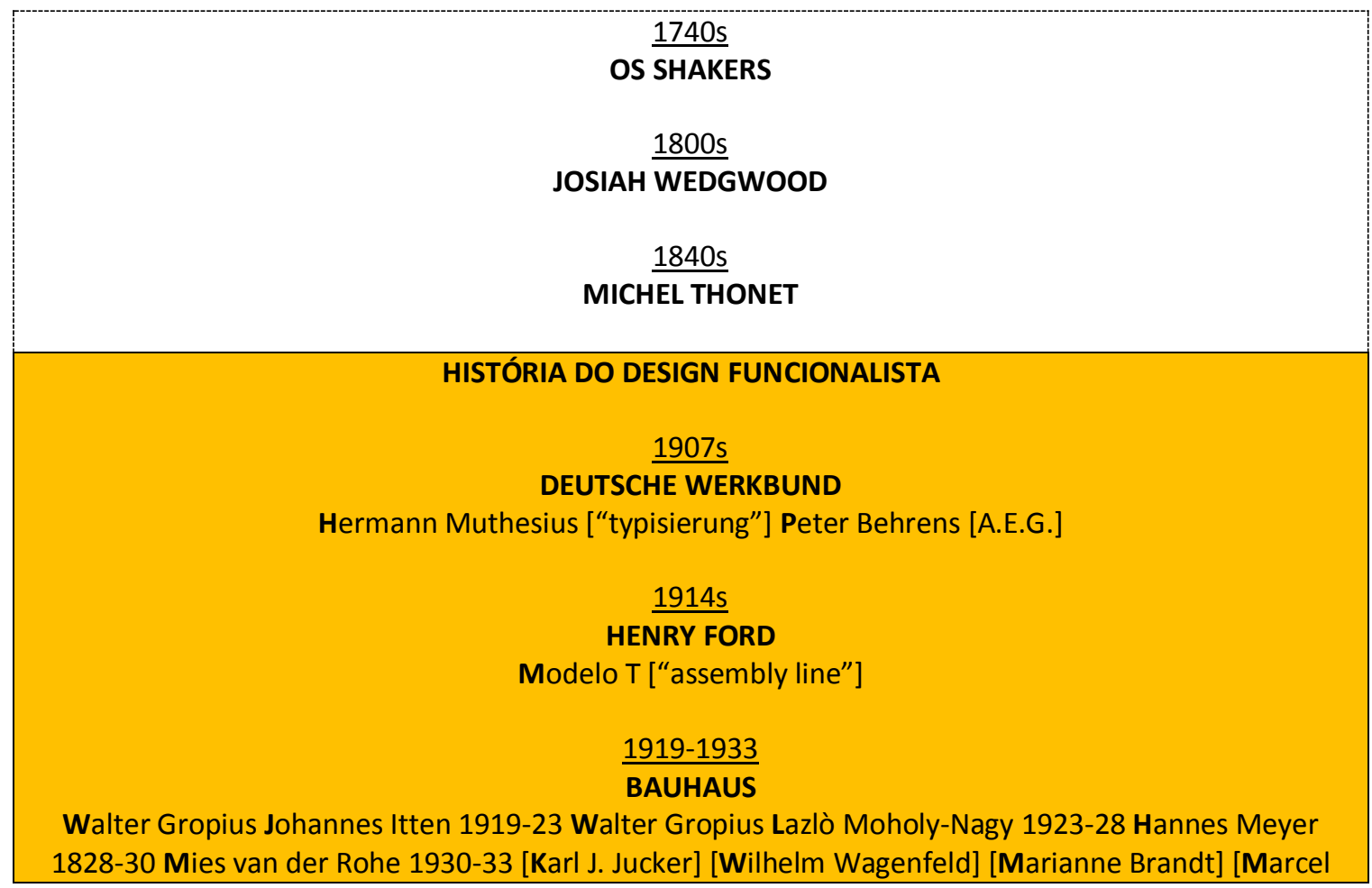




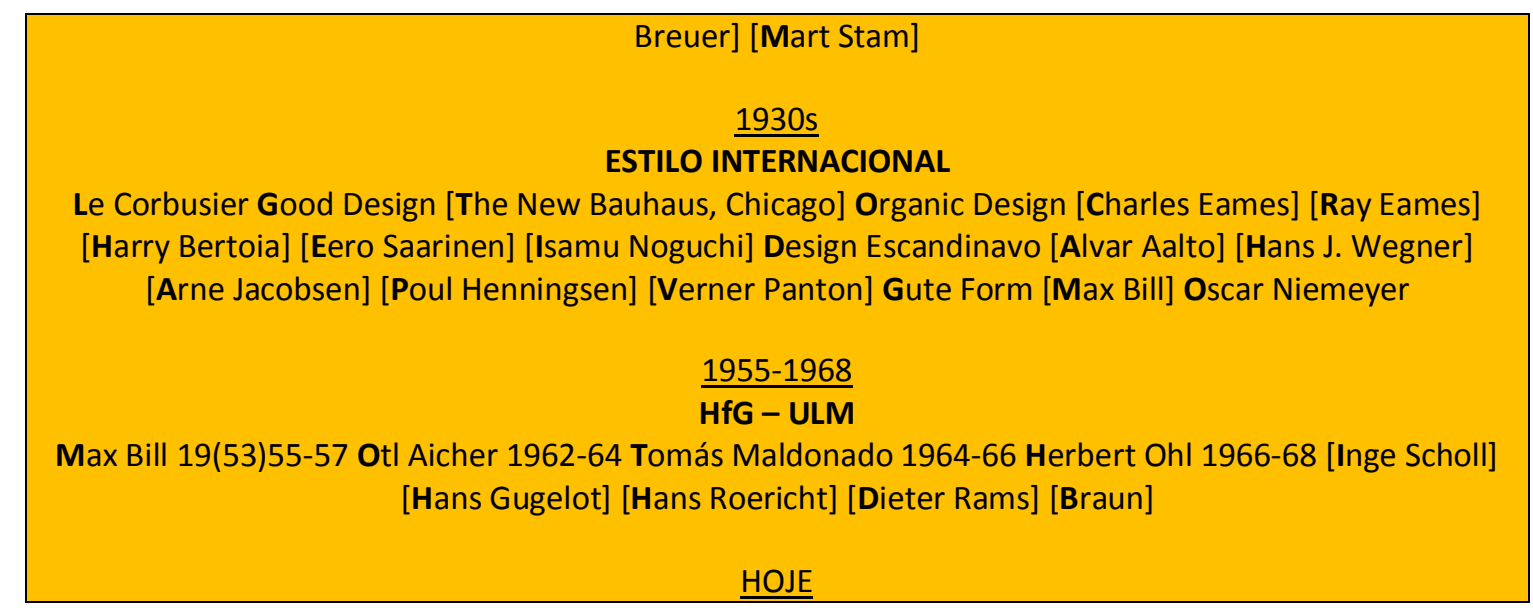

Figura 4 - Linha do tempo da História do Design Funcionalista.

Fonte: "Elaborado pelo autor, com base na pesquisa realizada"

Na história do Design Funcionalista, caracterizo o design funcionalista como aquela linha do tempo que "nasce da teoria do funcionalismo, segundo a qual, a forma é determinada pela função e toda decoração é desnecessária - até prejudicial, porque ela atrapalha a produção industrial de massa e aumenta desnecessariamente o custo dos bens manufaturados" [HAUFFE, 1998: 80] e "a crença geral era a de que formas simples e geométricas eram mais consistentes com a produção industrial" [Id.: Ibid.]. Contextualizo os produtos funcionalistas nos âmbitos das soluções "técnicoformalistas", "técnico-produtivista" e "técnico-utilitarista" [MALDONADO, 1993: 59, 69-73].

\subsection{História do Styling}

Para marco temporal do início da História do Styling, não haveria como não adotar o ano do "crack" da bolsa de New York como tal. E como recorte geográfico, o exemplo pioneiro dos designers da américa do norte. Mas aqui também trabalho numa perspectiva pré-histórica do Styling, abordando a história de Louis Chevrolet, que foi o primeiro grande adversário do funcionalismo de Henry Ford, além de, é óbvio, quase não precisar mostrar que a história do styling continua muito viva.

\begin{tabular}{|c|}
\hline $\begin{array}{l}\frac{1920 \mathrm{~s}}{\text { GENERAL MOTORS }} \\
\text { Louis Chevrolet }\end{array}$ \\
\hline HISTÓRIA DO STYLING \\
\hline $\begin{array}{c}\frac{1929 \mathrm{~s}}{\text { O “CRACK” DA BOLSA DE NY }} \\
\text { Walter Dorwin Teague Norman Bell Geddes Henry Dreyfuss Raymond Loewy }\end{array}$ \\
\hline $\begin{array}{l}\frac{1945-1960 \mathrm{~s}}{\text { MILAGRE ECONÔMICO }} \\
\text { Cadillacs }\end{array}$ \\
\hline$\frac{1973 \mathrm{~s}}{\text { CRISE DO PETRÓLEO }}$ \\
\hline “OVO KINDER" \\
\hline
\end{tabular}




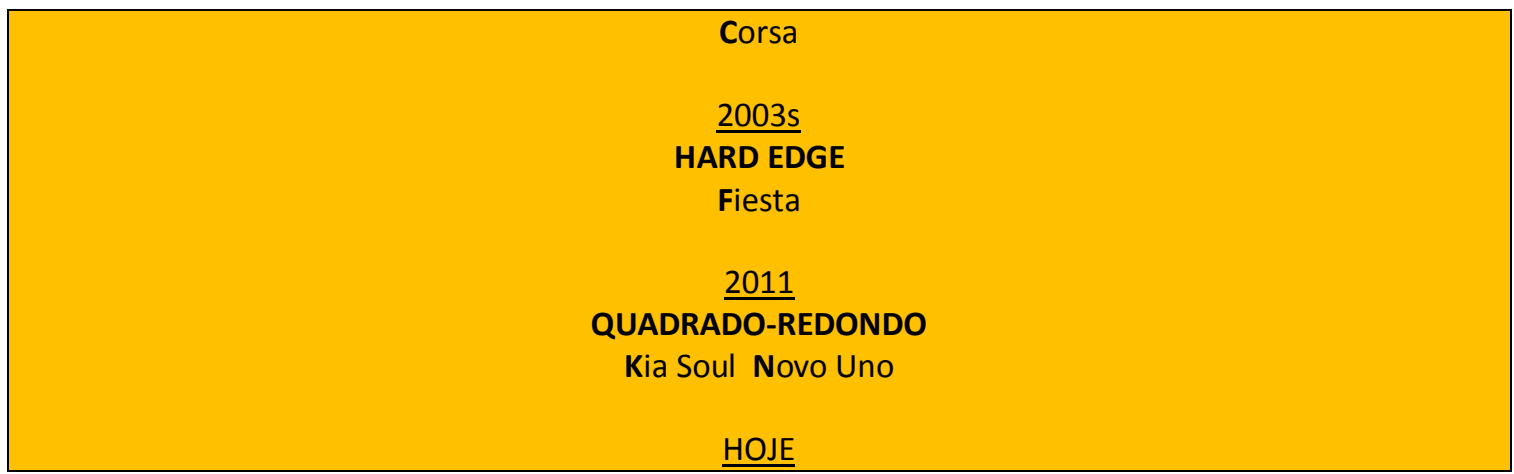

Figura 5 - Linha do tempo da História do Styling.

Fonte: "Elaborado pelo autor, com base na pesquisa realizada"

A história do Styling é contextualizada no âmbito socioeconômico e considero projetos de styling aqueles produtos que tem sua forma determinada através de uma lógica muito próxima da lógica gratuita da moda [DORFLES, 1978: 59-62].

\subsection{História do Design Pós-Modernista}

Por fim, localizo a pré-história do Design Pós-Modernista nos experimentalistas italianos do pós segunda-guerra e marco como seu início as criações dos Designers "Pop", também italianos, dos anos 1960. Atravesso por entre os muitos "studios", "gruppos" e aventuras do Anti-Design Radical, chego ao Studio Alchimia e ao Gruppo Memphis, ainda na Itália. Daí ao chamado "New Design" [HAUFFE, 1998: 157], na falta de uma denominação melhor, para a internacionalização das estratégias de design características desta linha do tempo que também se estende até o presente.

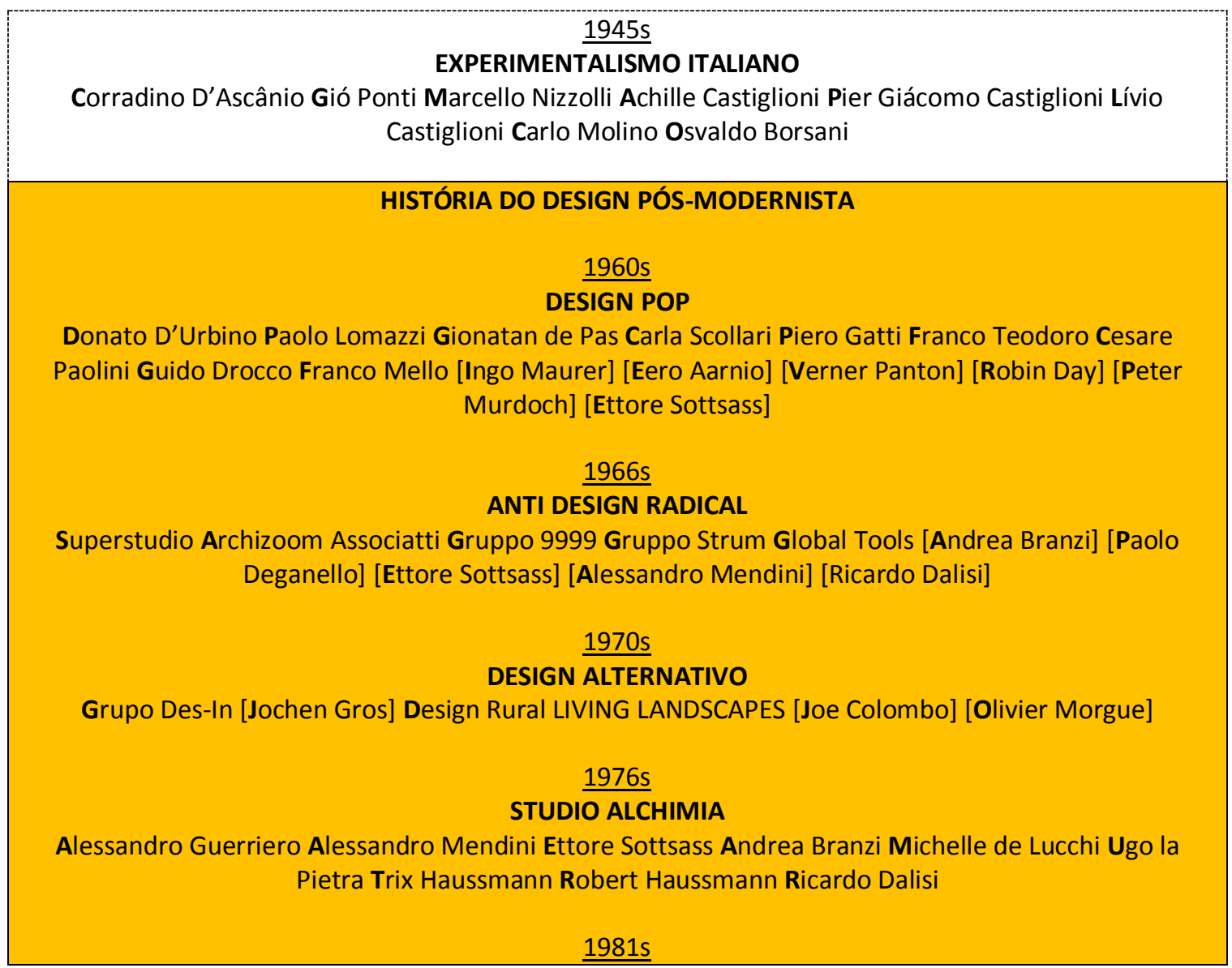


GRUPO MEMPHIS

Ettore Sottsass Andrea Branzi Michelle De Lucchi Martine Bedin [Mateo Thun] [Michael Graves] [Arata Isozaki] [Natalie du Pasquier] [Hans Hollein] [Peter Shire] [Paolo Deganelo] [Barbara Radice ]

\section{$\underline{1985 s-H O J E}$ \\ NEW DESIGN}

ALEMANHA Grupo Styletto [Frank Schreiner] Grupo Möbel Perdu [Claudia Schneiber-Esleben] [Michel Feith] Grupo Pentagon [Wolfgang Laubersheimer] [Gerd Arens] [Ralf Sommer] [Reinhard Müller] [Detlef Meyer-Woggenreiter] Grupo Cocktail [Renate von Brever] [Heike Mühlhaus] Grupo ginbAnde [Klaus-Achim Heine] [Uwe Fischer] Grupo Kunstflug [Heiko Barthels] [Harald Hullmann] [Hardy Fischer] Michael Syniuga Jörg Hundertpfund Sylvia Rohbeck [Outros] ITÁLIA Gaetano Pesce [Borek Sipek] [Shiro Kuramata] [Outros] INGLATERRA Ron Arad Jasper Morrisson Tom Dixon Dany Lane [Outros] ESPANHA Oscar Tusquets Blanca Javier Mariscal [Outros] FRANÇA Philippe Starck [Marie-Christine Dorner] [Elizabeth Garouste] [Mattia Bonetti] [Thierry Lecoute] [Andrée Putman] [Kristian Gavoile] [André Dubreil] [Outros] HOLANDA Droog Design BRASIL Luciano Deviá Irmãos Campana Walter Bahcivanji

Figura 6 - Linha do tempo da História do Design Pós-Moderno.

Fonte: "Elaborado pelo autor, com base na pesquisa realizada"

A história do Design Pós-Modernista é contextualizada no âmbito da criação de cultura material e envolve projetos de produtos que, de certo modo, se voltam "contra o funcionalismo bem como contra o domínio da grande indústria e das instituições de design" [HAUFFE, 1998: 141].

\subsection{Tipos de Avaliação dos Alunos}

Com exceção dos exames finais, desde 2011 todos os trabalhos realizados pelos alunos são do tipo de trabalho de pesquisa, que podem ser individuais ou em equipes e que são materializados preferencialmente na forma de vídeos digitais de até 10 minutos.

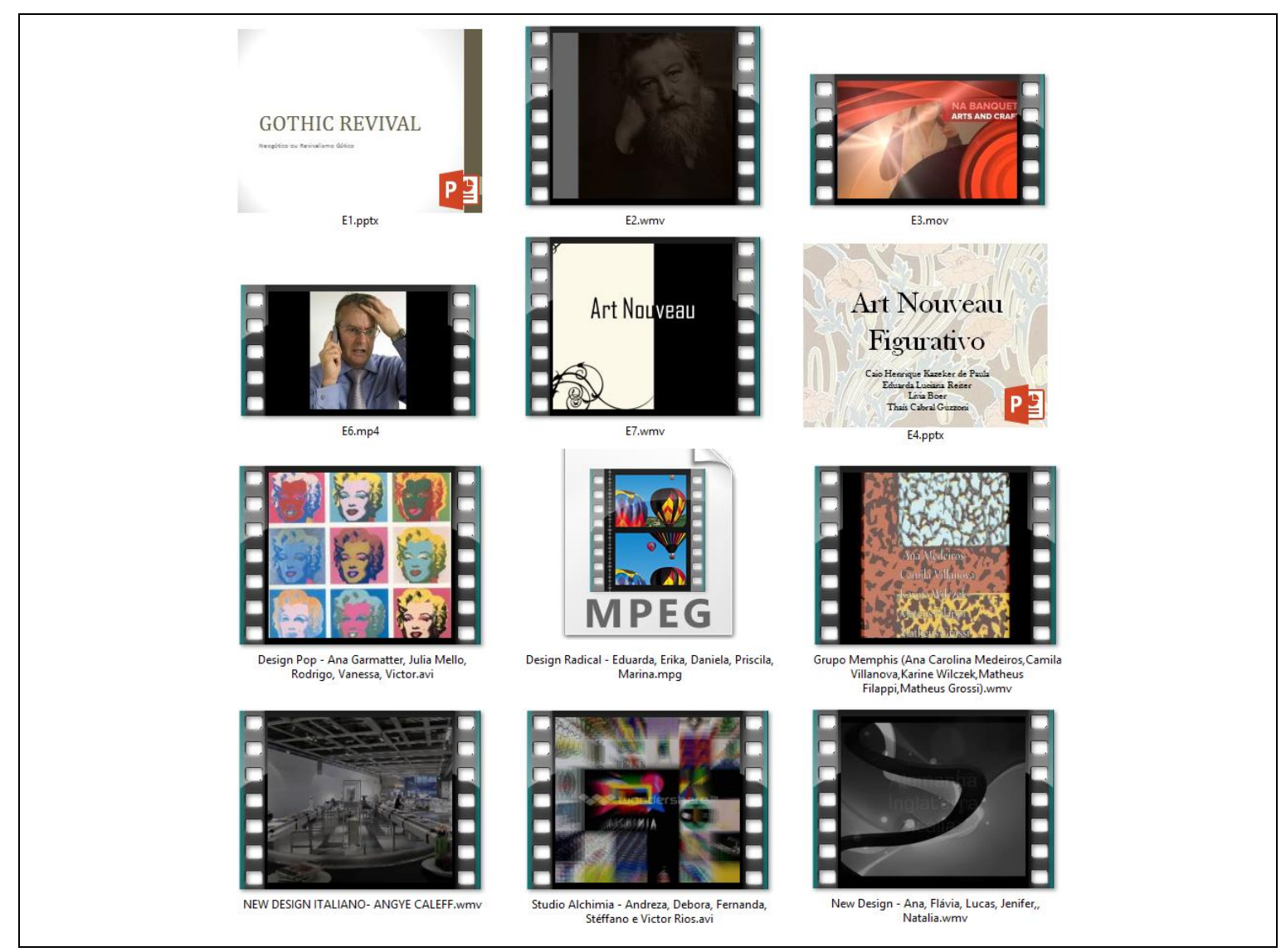


Figura 7 - Ícones de arquivos de filmes escritos, produzidos, dirigidos e montados pelos alunos da disciplina de História do Design de Produto da UFPR.

Fonte: "Elaborada pelo autor, com base na pesquisa realizada".

Escolhi esta estratégia de avaliação porque acabei percebendo que os jovens de 17, 18 anos têm uma facilidade enorme em lidar com o audiovisual (além de já começarem a se exercitar para fazer o vídeo de um minuto que será cobrado deles na apresentação de seus TCCs)

Além disso, acabei percebendo que o modelo de aulas expositivas com o auxílio de projeção de slides, que funcionava tão bem para os alunos da minha geração, já não motivava os alunos das últimas e atuais gerações.

Hoje, a cada um dos quatro bimestres da disciplina, ainda dou aulas expositivas no início de cada um deles, apresentando a linha ou as linhas de tempo que serão trabalhadas ao longo deles, contextualizo-as através da explicitação daquelas características que as tornam individuais em relação às outras e forneço uma relação bibliográfica e de sites de consulta confiável.

A partir daí, divido a turma em equipes que começam o trabalho de pesquisa histórica de alguns dos itens da linha ou das linhas de tempo em foco, e os alunos começam o trabalho de coleta de material audiovisual relacionado ao tema. Faço acompanhamento e discussão semanal da evolução do trabalho de cada uma das equipes, desde essa fase, passando à da seleção e organização da informação pertinente, até a elaboração do storyboard, do filme propriamente dito, de sua projeção para a turma e da sua disponibilização digital para, pelo menos, o público da sala.

\subsection{Como os Alunos Percebem e Avaliam a Disciplina²}

1) De 1 a 5, quão comprometido é o(a) professor(a) com as aulas e os alunos?

R: 3,25

2) Você acha a didática da disciplina funcional?

R: Sim 16 x 13 Não

3) Você se sente à vontade para tirar dúvidas com o(a) professor(a) dentro $e$ fora da sala de aula?

R: Sim $27 \times 2$ Não.

\section{CONCLUSÃO}

A experiência de "chão-de-sala-de-aula" tem mostrado que, com respeito à metodologia de ensino adotada em 2011, a de substituir a estratégia de aulas expositivas e o consequente trabalho ou prova de aproveitamento pela estratégia de orientar um trabalho de pesquisa para a elaboração de um filme, ajustes anuais têm sido feitos.

Especialmente em relação à circulação do acervo audiovisual entre os alunos da turma. Em 2011-12 a novidade trouxe um certo "frisson" e, consequentemente, uma certa curiosidade pelo resultado obtido pelas outras equipes.

\footnotetext{
2 Dados colhidos da avaliação sistemática que o CADI (Centro Acadêmico de Desenho Industrial do Curso de Design da UFPR) tem efetuado ao longo dos últimos anos através da sua COADD (Comissão Organizadora da Avaliação Discente Docente); neste caso, avaliação de 2013.
} 
Em 2013 o fenômeno começou a se inverter, o interesse pelo resultado das outras equipes passou a ser praticamente desprezado. Todos nós estávamos exaustos por causa do calendário de recuperação dos dias parados na última greve, é verdade, mas isso não me impediu de perceber que estava faltando na disciplina uma motivação para o acompanhamento dos resultados obtidos pelas outras equipes que não a sua.

Ainda em 2013 tentei transformar alguns daqueles atendimentos semanais individualizados para cada uma das equipes de trabalho em atendimentos públicos, mas esbarrei em outro problema: ou o material pesquisado ainda não estava suficientemente organizado para caracterizar um momento de transferência de significado coerente ou estava tão organizado e tão próximo do resultado final que muitas informações já disponíveis foram boicotadas para não descaracterizar o efeito surpresa que cada equipe sempre procura buscar, "pois somos todos designers desde o primeiro ano, não é"!

Agora, em 2014, a estratégia adotada é a de trazer os alunos para tomarem parte ativa no processo avaliativo. A ideia é fazer uma ou duas sessões de projeções adicionais à da "avant première" e estimular os alunos a debater e selecionar os melhores dos piores filmes. Estratégia "Oscar"?

E, para terminar, as perguntas que eu me faço e que devolvo aos presentes e aos leitores futuros:

1) A UFPR é a única instituição nacional de ensino de design que trabalha com a modalidade de mais de uma linha de tempo para narrar a história do design?;

2) A UFPR está razoavelmente certa ou absolutamente equivocada ao advogar a modalidade de mais de uma linha de tempo para a narração da história do design?

\section{REFERÊNCIAS}

BRAGA, Marcos da Costa; STEPHAN, Auresnede Pires. "Apresentação do evento": Folder do Seminário Paulista do Ensino da História do Design. São Paulo: Centro Universitário Maria Antônia da USP, 2014.

DORFLES, Gillo. O Design Industrial e a sua Estética. São Paulo: Martins Fontes, 1978.

HAUFFE, Thomas. Design: a Concise History. London: Laurence King, 1998.

MALDONADO, Tomás. El Diseño Industrial Reconsiderado. 3a ed. Barcelona: Gustavo Gili, 1993.

PEVSNER, Nikolaus. Os Pioneiros do Desenho Moderno: de William Morris a Walter Gropius. São Paulo: Martins Fontes, 1980.

READ, Herbert. Arte e Industria: Principios de Diseño Industrial. Buenos Aires: Infinito, 1961. 